NBER WORKING PAPER SERIES

COST-BENEFIT ANALYSIS UNDER UNCERTAIMTY

\author{
Danlel A. Graham
}

Work1ng Paper No. 194

CENTER FOR ECONOMIC ANALYSIS OF HUMAN BEHAVIOR AND SOCIAI INSTITUTIONS National Bureau of Economic Research. Inc. 261 Madison Avenue, New York, N.Y. I0016

\title{
August 1977
}

Preliminary; Not for Quotation

NBER working papers are distributed informally and In 11mited number for comments only. They should not be quoted without written permission.

This report has not undergone the review accorded official IBER nublications; in particular, it has not yet been submitted for approval by the Board of Directors.

Research for this paper was supported by a grant from the Robert Hood Johnson Foundation to the NBER. 


\title{
COST-BENEFIT ANALYSIS UNDER UNCERTAINTY
}

\author{
Daniel A. Graham
}

\section{Introduction}

The implications of uncertainty for cost-benefit analysis remain controversial. Two related problems are the subject of this analysis. First, for any given future period a dollar magnitude must be identified which appropriately represents the value of the uncertain benefits (costs) to accrue in that year. Second, an appropriate discount rate for converting this future value into present value must be identified.

For illustrative purposes consider a simple problem. The construction of a dam is being considered. Potential benefits include flood control in wet years and the provision of irrigation water in dry years. A standard approach to determining the value of this dam employs the probabilities of wet and dry years together with the value of benefits to accrue under each circumstance to calculate the expected value (mathematical expectation) of benefits in each year. Thus, for examole, if there were two possible states of nature within a given year--"wet" and "dry" with probabilities .7 and .3 respectively, and if a particular farmer were willing to pay up to $\$ 50$ for the dam if a wet year were certain and up to $\$ 100$ if a dry year were certain, then $\$ 65$ would be counted as the value of benefits accruing to the farmer in the given year. Adding across affected individuals would then yield the total benefit for the year.

Having obtained a measure of the total value of the dan within each year, the standard approach then involves discounting these benefits to 
obtain the present value, with the discount rates to be selected so as to appropriately reflect the riskiness of the benefits. Needless to say, there has been considerable controversy regarding the appropriate discount rate. 1

In addition to the debate regarding the discount rate there has recently surfaced a second controversy regarding the use of expected value as a measure of benefit within a period. If the farmer in the example were willing to pay $\$ 50$ for the dam contingent upon the occurence of the state "wet" and $\$ 100$ contingent upon "dry" what is the maximum sure payment that he would be willing to make in both states? Following Burton Weisbrod (1964) the term "option price" has been used to describe this maximum sure payment. Millard Long (1967) asserted that option price is nothing more than the expected value of surplus or $\$ 65$ in our example. Cotton Lindsay (1969) disagreed and Charles $\mathrm{J}$. Cicchetti and A. Myrick Freeman III (1971) and then John Krutilla et al (1972) argued that option price should generally exceed the expected value of surplus so that in our example the farmer should be willing to pay more than $\$ 65$ to insure the availability of the dam. More recently, Richard Schmalensee (1972) and Claude Henry (1974) have shown that option price depends upon individual preferences and may either exceed or be less than the expected value of surplus. This result is, of course, troublesome for the analyst wishing to employ cost-benefit analysis. Having available estimates of the expected value of surplus for the farmer as well as his option price, which number is to be used as a measure of his

${ }^{1}$ see, for example, the discussion in Arrow and Lind (1970). 
benefit for the period? To what extent does the answer to this question affect the choice of the appropriate discount rate?

In what follows we provide a conceptually correct procedure for determining whether a risky project passes the "potential pareto improvement" welfare criterion which forms the normative basis of costbenefit analysis. In this approach the role of secondary markets in providing opportunities for redistributing risk is made transparent and the modifications necessary when such markets do not exist are suggested. Some of the more interesting results include:

(1) Option price is the appropriate measure of benefit in situations involving similar individuals and collective risk.

(2) Expected value calculations are appropriate to situations involving similar individuals and individual risks.

(3) Whether or not option price exceeds the expected value of surplus is largely irrelevant to the evaluation of risky projects.

(4) In a wide range of circumstances, including incomplete markets, discounting for risky projects should be done at the riskless rate.

\section{The Willingness to Pay Locus}

To gain insight into the appropriate measure of uncertain benefits within a given period we shall continue the example of the dam. To make matters more precise suppose there are two goods the first of which will 
be called "dollars" while the second is the proposed dam. As before there are two possible states of nature, "wet" and "dry" with probabilities .7 and .3, respectively. Following the state preference approach of Arrow (1964) we suppose that the farmer is endowed with claims to the first good contingent upon which state occurs: $e_{w}$ dollars to be received if "wet" occurs and $e_{D}$ dollars if "dry." Using the von Neunan-Morgenstern theorem as extended by Hirshleifer (1965) the farmer's utility function can be represented as

$$
U=.7 U_{W}\left(c_{W^{\prime}} \delta\right)+.3 U_{D}\left(C_{D^{\prime}} \delta\right)
$$

where $c_{W}$ and $c_{D}$ represent claims to dollars contingent upon "wet" and "dry," respectively, and $\delta$ depicts the availability of the dan $(\delta=1$ indicates that the services of the dam are available to the farmer under specified terms and $\delta=0$ indicates that they are not).

The standard assumptions are made that

Non-satiation: $\quad v_{i}^{\prime}\left(c_{i}, \delta\right) \equiv \frac{\partial \nabla_{i}}{\partial c_{i}}>0 \quad i=w, D$ Risk Aversion: $\quad u_{i}^{\prime \prime}\left(c_{i}, \delta\right) \equiv \frac{\partial^{2} u_{i}}{\partial c_{i}^{2}}<0 \quad i=\omega, D^{2}$

2 There seems to be some confusion in the literature regarding the meaning of the term risk-aversion; see, for example, Schmalensee (1972), p. 815. The assumption as stated is sufficient to assure that the farmer would decline any fair, independent gamble. Suppose, for example, that given his endowment $e_{W}, e_{D}$ he were given the chance to make any fair bet he wished on the toss of a (fair) coin. Supposing the outcome of the coin toss to be 
The terms "expected surplus" and "option price" may now be nade precise. Define $S_{1}, I=W, D$ by the requirement

$$
v_{1}\left(e_{1}-s_{1}, 1\right)=u_{1}\left(e_{1}, 0\right) \quad i=w, D .
$$

Then the expected value of surplus is

$$
E\left(s_{1}\right) \equiv .7 s_{W}+.3 s_{D}
$$

\section{2 (concluded)}

distributed independently of the states "wet" and "dry" we have four states: "wet" and heads," "wet and tails," etc. Let the bet pay $x$ if heads and $y$ if tails with $.5 x+.5 y=0$, then the utility of accepting the gamble is

$$
\begin{aligned}
\hat{U} & \equiv .7\left[.5 U_{W}\left(e_{W}+x, \delta\right)+.5 U_{W}\left(e_{W}+Y, \delta\right)\right] \\
& +.3\left[.5 U_{D}\left(e_{D}+x, \delta\right)+.5 U_{D}\left(e_{D}+Y, \delta\right)\right]
\end{aligned}
$$

while the utility of declining the bet is

$$
\bar{v} \equiv .7 U_{W}\left(e_{W}, \delta\right)+.3 U_{D}\left(e_{D}, \delta\right)
$$

But risk aversion and $x, y \neq 0$ imply that

$$
\begin{gathered}
.5 v_{i}\left(e_{i}+x, \delta\right)+.5 v_{i}\left(e_{i}+y, \delta\right)<v_{i}\left(e_{i}{ }^{\prime}\right. \\
i=W, D .
\end{gathered}
$$

Thus $\hat{\mathrm{U}}<\overrightarrow{\mathrm{U}}$ and the bet would be declined. On the other hand, gambles which are not independent of existing risks afford the individual an opportunity to buy insurance. It would surely be a misnomer to define risk aversion. in a way that requires an individual to refuse the chance to buy fair insurance against an existing risk and yet this is the definition schmalensee proposes. 
Option price, on the other hand, is defined by the requirement:

$$
\begin{aligned}
& .7 U_{W}\left(e_{W}-O P, 1\right)+.3 U_{D}\left(e_{D}-O P, 1\right)= \\
& .7 U_{W}\left(e_{W^{\prime}} 0\right)+.3 U_{D}\left(e_{D^{\prime}} 0\right) \equiv \bar{U}
\end{aligned}
$$

Option value is defined as the difference

$$
O V \equiv O P-E\left[s_{i}\right]
$$

We may now introduce a concept which will prove crucial to subsequent analysis. The "willingness to pay locus" consists of ordered pairs $\left(\gamma_{W^{\prime}} \gamma_{D}\right)$ satisfying

$$
.7 U_{W}\left(e_{W}-\gamma_{W^{\prime}} 1\right)+.3 U_{D}\left(e_{D}-\gamma_{D^{\prime}} 1\right)=\bar{U}
$$

where $\bar{U}$ is defined in equation (3). By construction, the farmer would as soon make any of the contingent payments $\left(\gamma_{W}, \gamma_{D}\right)$ for the dam as do without it. Notice, moreover, that the previously defined magnitufes $S_{W^{\prime}} S_{D}$ and oP correspond to particular points along this willingness to pay locus, i.e.

$$
\left(\gamma_{W^{\prime}} \gamma_{D}\right)=\left(S_{W^{\prime}} S_{D}\right)=(\$ 50, \$ 100)
$$

is one point on the locus and

$$
\left(Y_{W}, Y_{D}\right)=(O P, O P)
$$


is another. This is illustrated in Figure 1. The concavity which is illustrated for the locus follows directly from the assumption of risk aversion.

A further point along the locus which might be called the "certainty point" may be identified for expository purposes. Let $\left(\gamma_{\psi^{*}}^{\star} \gamma_{D}^{\star}\right)$ be that point on the locus satisfying ${ }^{3}$

$$
U_{W}\left(e_{W}-\gamma_{W^{*}}^{*} 1\right)=U_{D}\left(e_{D}-\gamma_{D^{*}}^{*}, 1\right)
$$

Were the farmer to contract for these contingent payments for the dam he would be indifferent as to which state of nature occurs. Put somewhat differently, he would have, in the process of contracting for these contingent payments, simultaseously acquired a completely insured position against the uncertain state of nature.

A related reference point on the locus may be labeled the "fair bet" point and defined by the requirement that $\left(Y_{W^{\prime}}^{\prime}, Y_{D}^{\prime}\right)$ belong to the locus and satisfy ${ }^{4}$

3 This existence of this point is assured by continuity of the willingness to pay locus, $\gamma_{D}=f\left(\gamma_{W}\right)$, together with the assumption.

$$
\begin{aligned}
& U_{W}(0,1) \leq \delta_{D}\left[e_{D}-f\left(e_{W}\right), 1\right] \\
& U_{W}\left[e_{W}-f^{-1}\left(e_{D}\right), 1\right] \geq U_{D}(0,1)
\end{aligned}
$$

4 The fair bet point corresponds to that point where the absolute value of the slope of the locus is equal to the odds of a wet year, .7/.3. To see this notice that the slope of the locus at $\left(Y_{W^{\prime}}^{\prime} Y_{D}^{\prime}\right)$ is given by 


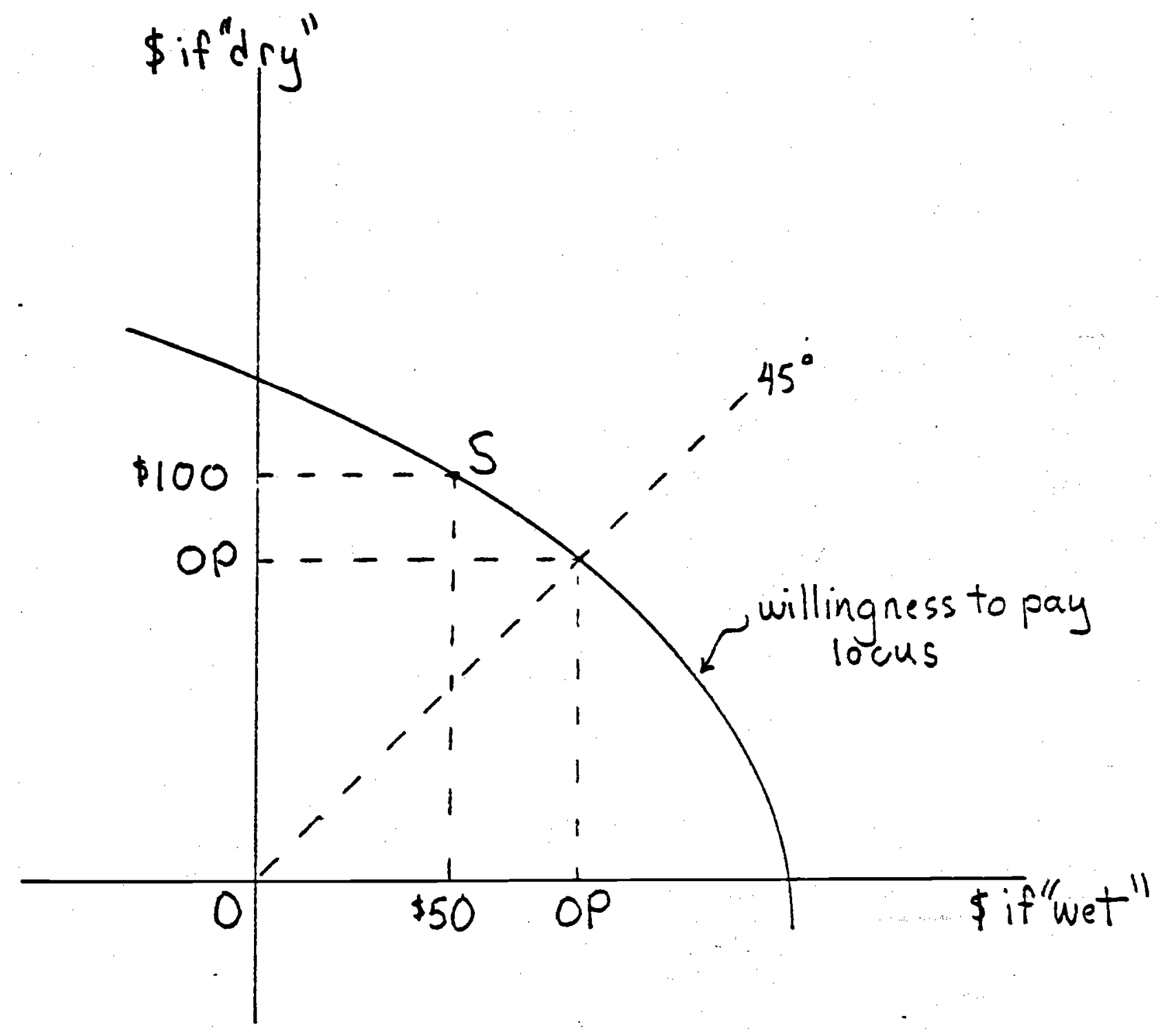

Figure 1 
(7)

$$
U_{W}^{\prime}\left(e_{W}-Y_{W^{\prime}}^{\prime} 1\right)=\sigma_{D}^{\prime}\left(e_{D}-Y_{D^{\prime}}^{\prime}, 1\right)
$$

Precise relationships among the surplus, certainty and fair bet points are developed in an appendix; here it is sufficient to point out that in general these are distinct points along the willingness to pay locus.

\section{Option Value}

The willingness to pay locus can be used to indicate the factors determining whether option value [equation (4)] is positive or negative. The possibilities are illustrated in Figures 2a-c. Figure $2 a$ is characterized by the fact that the fair bet point lies to the right of the $45^{\circ}$ line. Since the slope of the locus at this point gives the relative probability of "wet" versus "dry," a parallel through the surplus point

4 (concluded)

$$
\frac{d^{\gamma_{D}}}{d \gamma_{W}}=-\frac{.7 \sigma_{W}^{\prime}\left(e_{W}-\gamma_{W^{\prime}}^{\prime} 1\right)}{.3 U_{D}^{\prime}\left(e_{D}-\gamma_{D^{\prime}}^{\prime} 1\right)}=-\frac{.7}{.3}
$$

Now the locus is only defined for $\gamma_{W} \leqq e_{W}$ and $\gamma_{D} \leqq e_{D}$ since negative consumptions are not defined. Thus, in general there may be no actual tangency of the locus to a line shose slope represents the relative probabilities of the states but only a "corner solution." In such circumstances the corner solution can be used to define the fair bet point.
Alternatively. the assumption

$$
\lim _{x \rightarrow 0} U_{i}^{\prime}(x, 1)=\infty \quad i=N, D
$$

assures an interior tangency. 
- $8 \mathbf{a}-$

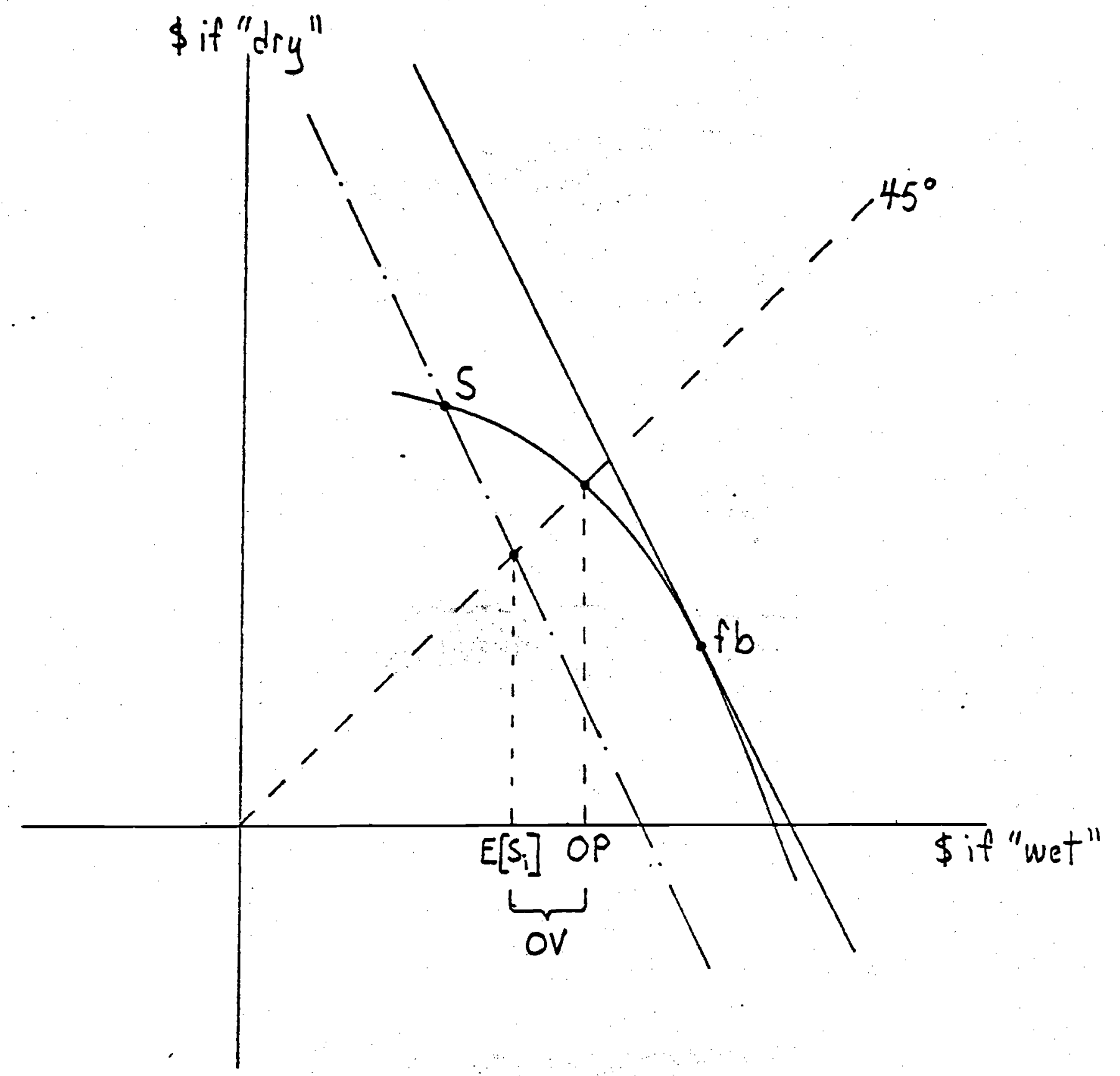

Figure $2 a$ 
S yields all payment combinations with the same expected value as the surplus point. Where this line crosses the $45^{\circ}$ line payments are equal in both states and thus also equal to the expected value of surplus. Here option price necessarily exceeds the expected value of surplus and thus option value is positive.

In Figure $2 b$ the fair bet point lies to the left of the surplus point and a similar construction reveals that, in this case, the expected value of surplus must exceed option price yielding a negative option value.

The third case illustrated in Figure $2 c$ is characterized by the fair bet point lying between the $45^{\circ}$ line and the surplus point. Here there is ambiguity: option price may be greater or less than the expected value of surplus.

\section{The Potential Pareto Improvement Test}

Figures $2 a-2 c$ not only sumarize the considerations affecting the sign of option value, they also suggest that there may be little to recommend either option price or expected surplus for a role of prominence in cost-benefit analysis. They are, after all, only two arbitrarily selected points along the willingness to pay locus and have no obvious claim to preference over other points along the locus including the fair bet and certainty points. The question to be resolved ultimately is whether or not there exist payments for each individual which, when aggregated, yield sufficient resources to build the dam and which. when coupled with the provision of the dan, leave no individual worse off then he would otherwise have been. This question can be answered as follows. Having developed the idea of the willingness to pay locus for one individual let us suppose 
that there are $\mathrm{N}$ people in the society and that the willingness to pay locus of the $i^{\text {th }}$ person is given by

$$
r_{D}^{1}=f^{i}\left(r_{W}^{i}\right) \quad i=1, \ldots, N
$$

The method of aggregating these curves is illustrated in Figure 3 and will immediately be recognized as analogous to the "community indifference curve" construction from international trade theory. The curve labeled wtp $p_{1}$ is drawn relative to an origin at $o_{1}$ and represents the willingness to pay locus of the first person. Similarly wto 2 is drawn relative to an origin at $\mathrm{O}_{2}$, and represents the locus of the second person. $O_{2}$ is positioned relative to $o_{1}$ so that (1) the two curves will be tangent and (2) the respective axes are parallel. The curve labeled $\sum_{i=1}^{2} w t_{1}$ represents the locus of all such possible positions for $\mathrm{O}_{2}$ and can be interpreted as the set of maximum payments that the first two individuals would collectively make for the dam. ${ }^{5}$ Notice that the slope of the aggregate curve at a given point is the same as the slope of the individual curves at the associated tangency point.

5 Alternatively, let $\Gamma_{i}$ be defined as the set of payments lying on or below the $i^{\text {th }}$ person's willingness to pay locus. By assumption $r_{i}$ is convex for all $i$. The aggregate willingness to pay locus is obtained as the upper boundary of the sum of these sets, $\sum \Gamma_{i} \equiv\left\{\gamma \mid \gamma=\sum Y_{i}, Y_{i} \varepsilon \Gamma_{i} i=1, \ldots . . N\right\}$. It is well known that the sum of convex sets is itself convex; thus the aggregate willingness to pay locus shares the concavity property of the individual curves. 
- $10 a-$

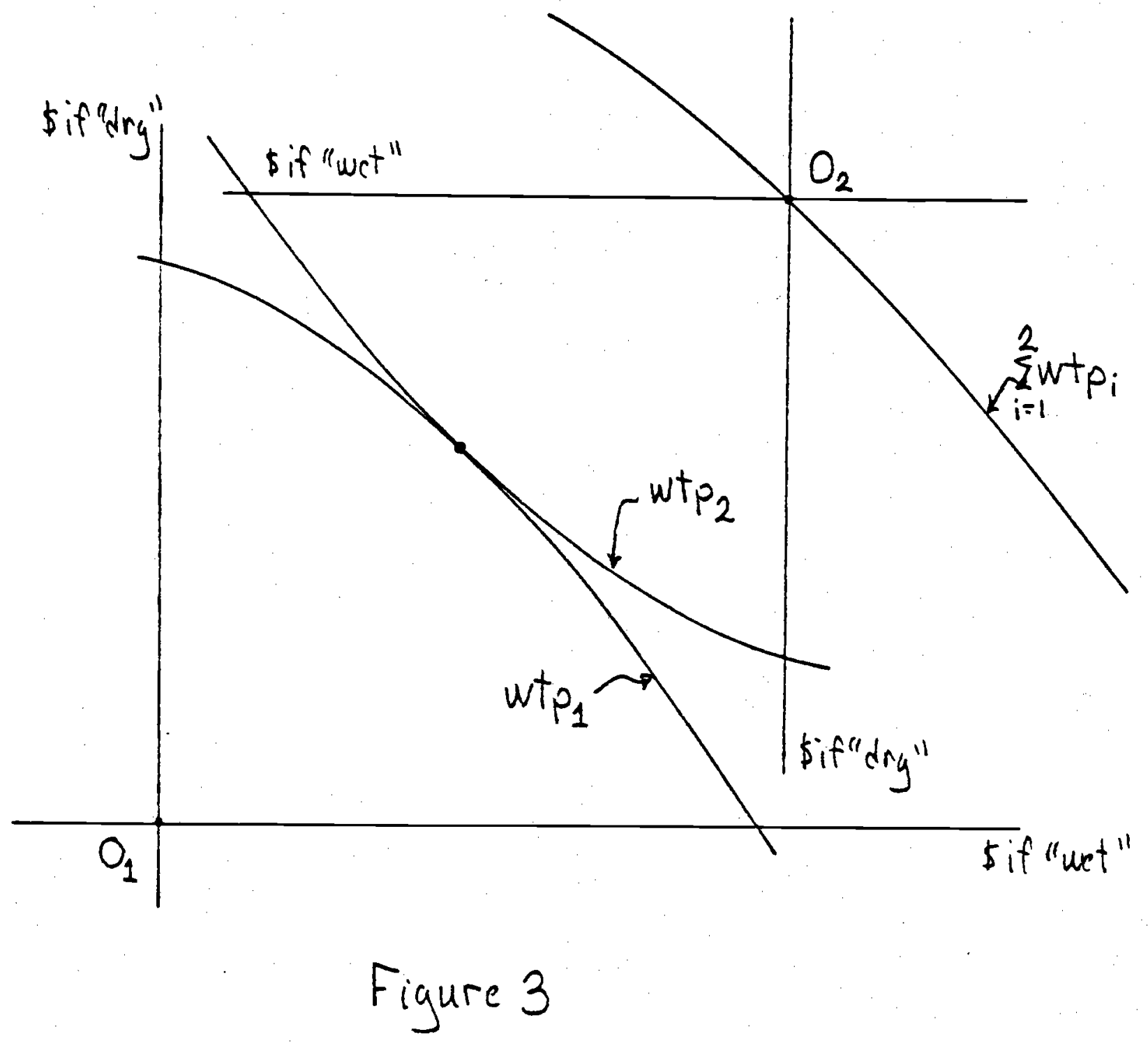


To this aggregate locus for the first two people is "added" the locus for the third individual and so forth obtaining in the end the aggregate locus for the entire society illustrated in Figure 4. The point labeled $V$ is the maximum sure payment that society as a whole would be willing to make for the dam and represents the magnitude that should be compared with a sure resource cost of building the dam. Should the cost of the dam itself be uncertain no appreciable difficulty is added. If, for example, the cost is to be $a_{W}$ in the state "wet" and $a_{D}$ in the state "dry," then the dam should be built on the potential Pareto improvement criterion since reference to Figure 4 indicates that society would be willing to sacrifice resources sufficient to cover actual costs in each possible state. (There are points on the aggregate locus to the northeast of A.) On the other hand, if resource costs are described by a point such as $B$ which lies above the aggregate locus then there does not exist a Pareto improving way of providing the dam.

It should be noted that if an aggregate payment such as $\mathrm{V}$ were actually to be collected with each person making a payment along his own willingness to pay locus, than a Pareto efficient distribution of risk would result. To see this notice first that the slope of the aggregate locus at $v$ is the same as the slope of each individual's locus at the implied payments point. But the slope of an individual's willingness to pay locus at a particular payments point is equal to his marginal rate of substitution between the two goods once the payments are contracted. Thus the marginal rates of substitution between "dollars if wet" and "dollars if dry" are equated for all individuals. Such a taxation scheme, therefore, is equivalent to establishing competitive markets for contingent dollar 
- 11a -

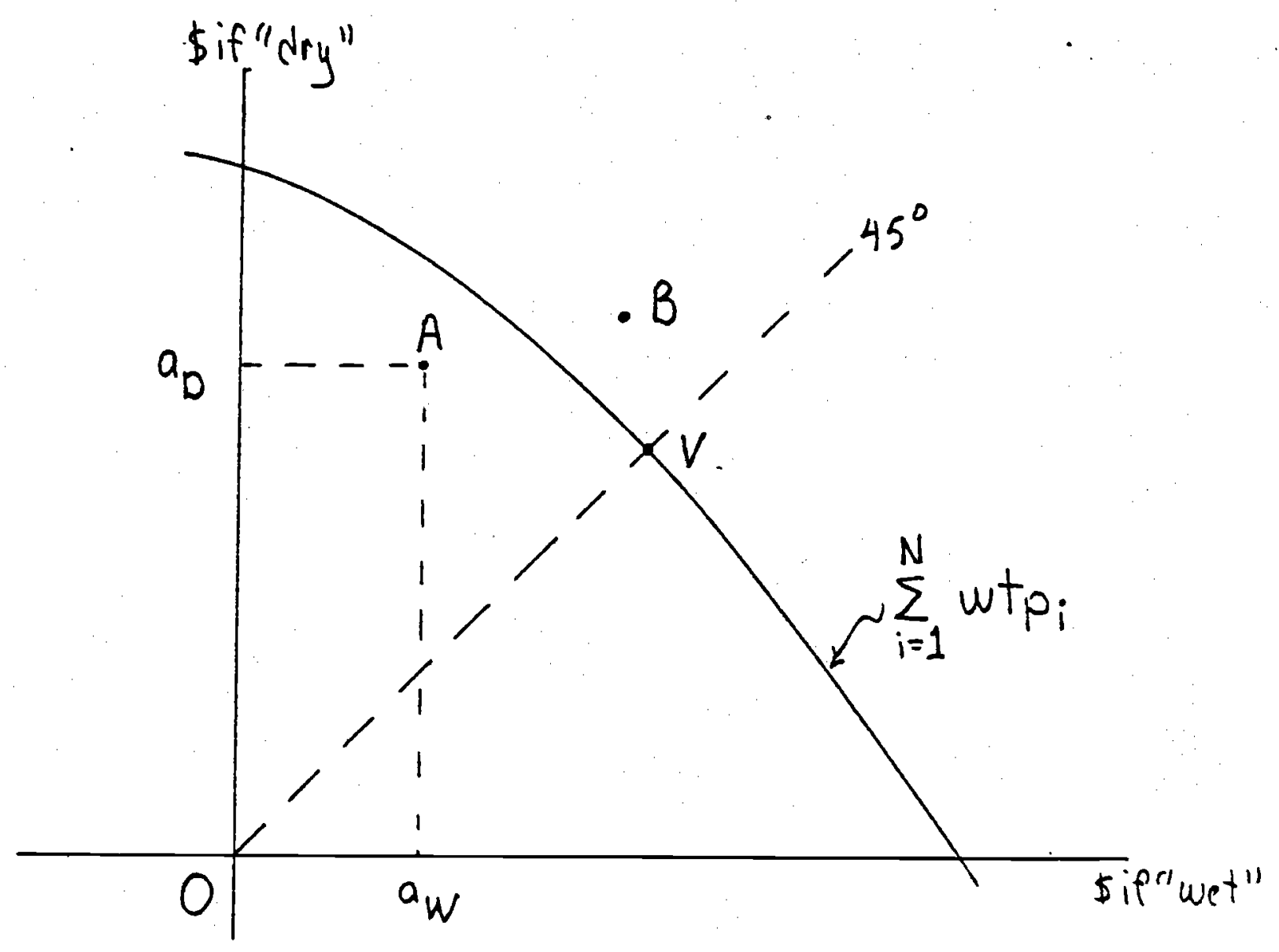

Figure 4 
claims against the two states with relative prices equal to the common marginal rate of substitution.

This, then, is the general answer regarding which of the points along the individual's willingness to pay locus is relevant to cost-benefit analysis. For each possible pair of contingent claims prices for the two states, select that payment combination for each individual which has the greatest value at these prices. Adding these payments across individuals yields a point on the aggregate willingness to pay locus. Justification of the project hinges upon the question of whether or not contingent prices exist at which aggregate willingness to pay in each state exceeds the corresponding resource cost of the project. Should such prices exist that point from an individual's locus which has the greatest value at these prices is the one relevant for cost-benefit analysis and the corresponding value at these prices is the appropriate measure of benefit.

\section{Special Cases}

It remains to determine whether option price or expected value calculations have any potential relevance to cost-benefit analysis. Consider first a special case in which (1) the resource cost of the dam is certain and (2) all individuals are alike--same utility functions and same endowed claims. Here we are concerned with the intersection of the aggregate locus with the $45^{\circ}$ line (point $v$ in Figure 4) since this point represents the largest possible sure payment. But with all individuals alike this aggregate payment entails each individual making a payment corresponding to the intersection of iis individual willingness to pay locus with the $45^{\circ}$ line. This payment, moreover, is simply the individual's option 
price. With individuals alike the initial distribution of risk is efficient and collecting the sure, option-price payment from each preserves this efficiency. Thus there exist circunstances in which option price is the appropriate measure of benefit.

The second type of special case to be considered involves the concept of "individual risks" discussed by Malinvaud (1973). The dam problem involves a "collective risk" since everyone will experience the state "wet" or everyone will experience the state "dry." Consider an alternative situation based upon an example from Schmalensee (1972). Here an individual can be in one of two "individual states." In the first he will have "a strong desire" to go to Yellowstone Park next sumer. In the second he will have no desire to go. What is different about this situation is that it is possible for one person to experience "individual state 1 " while another experiences "individual state $2 . "$

It is possible, of course, to place this problem within the original framework by identifying states of nature according to the experience of each individual. Thus "state 1 " might correspond to the situation in which each of the $N$ members of society experiences "individual state 1." similarly, "state 2 " might denote the case in which everyone except the $\mathrm{s}^{\text {th }}$ person experiences "individual state 1 " while the $N^{\text {th }}$ experiences "individual state 2." By expressing each person's willingness to pay locus in terns of contingent dollar claims against each of the $2^{\mathrm{N}}$ possible states it is possible to proceed exactly as before.

A considerable simplification is possible, however, if we assume (I) again that individuals are alike and have the same endowments (tine same "individual state $I$ " and "individual state 2 " utility functions and the 
same endowed claims to dollars contingent upon these individual states) and (2) that the probability distribution of states takes a particular form. For simplicity suppose that $\mathrm{N}$ is large and that the probability can be taken to be one that a total of. $3 \mathrm{~N}$ individuals will be in "individual state $1 "$ in a given period and $7 \mathrm{~N}$ will be in "individual state 2." While it is known with certainty what fractions of society will experience the alternative individual states, the fates of particular individuals are uncertain. 6 For any given person we simply suppose that the probability that he will be in "individual state I" is . 3 while the probability of "individual state $2 "$ is .7. The willingness to pay locus of a representative individual is illustrated in Figure 5. The surplus point $s$ indicates that the individual would be willing to pay up to $\$ 100$ above the costs of the trip for a visit to Yellowstone if he were certain of "individual state $I^{\prime \prime}$ and nothing if "individual state $2 "$ were certain. This yields an expected surplus of $\$ 30$.

As previously mentioned the discussion in Schmalensee (1972) focuses upon whether or not the individual's option price exceeds $\$ 30$. Here we will be concerned with the implications of individual risks. The fair bet point (labeled fb in Figure 5) represents that point where the slope of the locus equals (in absolute value) the odds of being in "individual state 1." The tangent to the locus at this point, then,

6 This situation is analogous to knowing how many wrecks will occur on the fourth of July weekend without knowing who will have them. 
$-14 a-$

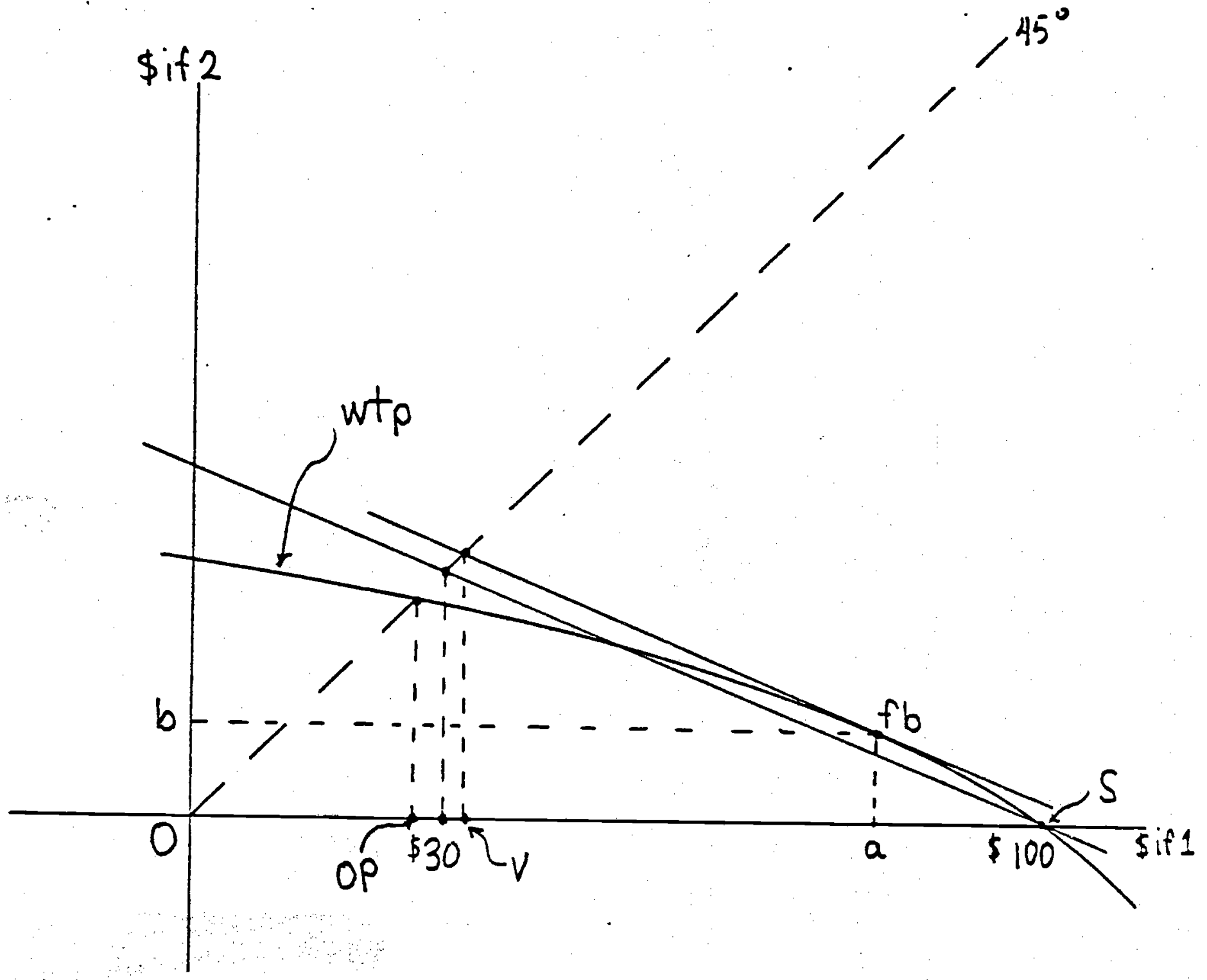

Figure 5 
represents alternative payment combinations with the same expected value. Since individuals are alike each is willing to make payments of oa " $\$$ if Individual state $1 "$ and $O b$ "\$ if individual state 2." The expected value of these payments is ov for each person. Moreover, since it is known that . 3N individuals will experience "individual state 1 " while .7N will experience "individual state $2 "$ the aggregate payment resulting from these individual payments would be

$$
\begin{aligned}
.3 \mathrm{~N} \cdot O \mathrm{Oa}+.7 \mathrm{~N} \cdot \mathrm{Ob} & =(.3 \cdot \mathrm{Oa}+.7 \cdot \mathrm{Ob}) \mathrm{N} \\
& =\mathrm{OV} \cdot \mathrm{N}
\end{aligned}
$$

Thus it is possible to collect an aggregate sure payment equal to $\mathrm{N}$ times the expected value of the fair bet point. Since no larger sure payment is possible, the fair bet point may, in these circunstances, be identified as the one appropziate to cost-benefit analysis. Alternatively, the expected value of the fair bet point is the appropriate measure of benefit.

This special case is an illustration of a more general proposition developed by Malinvaud (1973) which indicates circumstances in which equilibrium prices for contingent dollar claims against altemative states tend to be equal to the probabilities of the states. The simplified procedure followed in this case is made possible, in essence, by the knowledge that prices equal to the probabilities of the individual states will yield an efficient distribution of risk. Reference to Figure 5 indicates that this case is further characterized by the fact that the expected value of surplus, $\$ 30$, is greater than option price and, therefore, option value 
is negative. It would obviously be easy to illustrate a case in which option value is positive simply by drawing the willingness to pay locus so that it crosses the $45^{\circ}$ line above $\$ 30$. The sign of option value is, however, irrelevant. If expected values are relevant at all, i.e.. if the situation involves individual-insurable risks, then the expected value of the fair bet point is the largest of all points along the locus and is, therefore, the appropriate measure of benefit. If the situation does not involve individual-insurable risks then prices which support an efficient allocation of contingent claims will not in general be equal to probabilities and expected values have no bearing upon the appropriate "market price" value. 7

To restate, if individuals are alike then option price measures benefit in cases of collective risk while expected willingness to pay (the expected value of the fair bet point) measures benefit in cases of individual-insurable risks.

\section{Second Best Considerations}

The "hypothetical compensation test" of Raldor-Hicks and Scitorsky is the nomative basis of cost-benefit analysis as it is normally applied. In this approach it is sufficient for the justification of a project that

${ }^{7}$ Estimates of option price and the expected value of surplus may, of course, be used as lower bounds for the expected value of the fair bet point. It should be noted in this regard that an estimate of consumer surplus (the Hicksian compensating variation) derived from demand data for Yellowstone visitors would ideally estimate the expected value of surplus. To see this note that since. $3 \mathrm{~N}$ individuals visit the park each period with each having a surplus of $\$ 100$, one would obtain $\$ 30 \mathrm{~N}$, the aggregate expected value of surplus, from an ideal "area under the demand curve" type calculation. Since this measure is a lower bound for the true value Krutilla et al (1972) were correct in their suspicion that expected surplus understates the true benefit. 
a set of payments be identified for a project which (1) individuals would willingly make for the project rather than do without it and (2) cover the actual costs of the project. It is not commonly required that a taxation scheme be identified which collects from each individual payments commensurate with his willingness to pay. Thus actual financing of a justifiable project may collect an amount exceeding benefits from some individuals and an amount less than benefits from others. In such cases it is simply argued that the winners could, in principle, compensate the losers.

The issue of the actual method of financing a project assumes a more crucial role in cases of uncertainty for reasons which will soon be apparent. Consider the situation illustrated in Figure 6 . Here a society consisting of two people (who face a collective risk regarding the occurence of state 1 or state 2) is willing to make an aggregate sure payment corresponding to point $c$ for a particular project. Suppose that actual financing of the project entails a sure collection of $D$ from each. $\quad(C=2 D)$. This yields a surprising situation in which both people are worse off than they would have been without the project since $D$ exceeds the option price of each person. The difficulty stems from the fact that being willing to make an aggregate payment of $c$ is predicated upon achieving an efficient distribution of risk. Collecting payments corresponding to $A$ and $B$, respectively, from the first and second people equates their marginal rates of substitution between "\$ if state $1 "$ and "\$ if state $2 "$ and is, therefore, consistent with efficiency. Collecting payments corresponding to $D$ from each, on the 
$-17 a-$

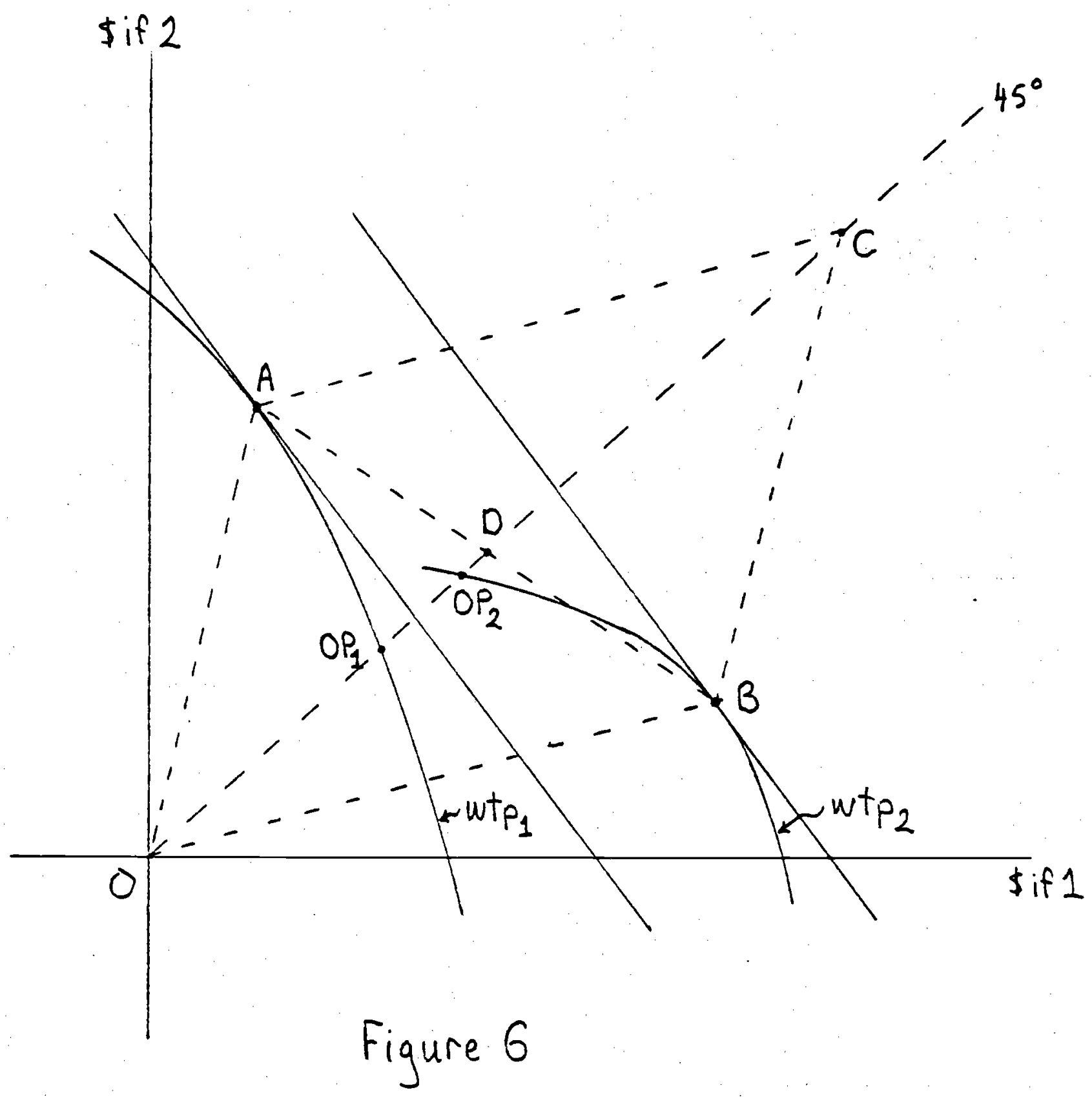


other hand, does not equate marginal rates of substitution and is inconsistent with efficiency unless secondary markets are available in which the individuals can buy and sell contingent claims.

The case of independent risks poses similar problems. Looking back at Figure 5 we see that both expected willingness to pay, $v$, and expected surplus exceed option price. Should actual financing entail sure collections of either $v$ or $\$ 30$ from each individual, everyone would be a loser in that situation as well unless a secondary market for insurance exists.

It is implicit in the original discussions of the "hypothetical compensation test" that complete markets exist for all goods. One need not be concerned with the allocational efficiency of taxation schemes in such curcumstances since trade in the perfect secondary markets assures ultimate allocational efficiency, However appropriate this "complete markets" assumption was for the riskless world of these original debates, it is generally conceded that many of the contingent claims markets required for allocational efficiency in a risky world do not exist. ${ }^{8}$ It is crucial in such circumstances that either (1) the particular method of financing the project be evaluated with respect to its implications for the distribution of risk or (2) the analysis be modified in such a way as to apoid dependence on non-existing markets.

8 There are at least two important reasons why many types of contingent claims markets do not exist. The first is moral hazard: a person buying claims contingent upon a particular state may have incentives to alter his behavior in a way that is adverse to the seller. Second, such markets require complicated and specialized contracts which may be costly both to write and to enforce. 
The problem can be put rather simply. The magnitude corresponding to $C$ in Eigure 6 represents society's willingness to pay for two things: the project itself and (2) an efficient allocation of risk. If the method of financing the project yields an efficient allocation it is legitimate to use $C$ as a measure of total benefit. If, on the other hand, the financing scheme does not produce efficiency then collecting C amounts to charging society for a benefit that has not been produced. 9 For these reasons option price may be regarded as a "second-best" measure of benefit appropriate to situations in which (1) actual financing involves sure collections from individuals and (2) secondary contingent claims markets are not available.

7. Discounting for Time and Risk

The modifications required to introduce time into the analysis are straightforward. In the case of the dam consider now a two period situation in which the services of the dam will be available at the beginning of the second period and simultaneously it will be discovered whether the second period is to be "wet" or "dry." For simplicity

${ }^{9}$ It might be thought that state-dependent collections represent an unrealistic method of financing projects. This is not necessarily true, however. In the case of the dam, for example, a combination of sure taxes and water charges might produce exactly the combination of contingent payments required for allocational efficiency. Sure taxes and visitor charges might similarly be used in the case of Yellowstone Park. In Figure 5 a sure tax of $O b$ in both states plus a visitor charge of $0 a-O b$ would produce exactly the desired result. In general, however, the same factors that prevent contingent claims markets from being privately organized would presumably inibit the use of state-dependent collection schemes. 
suppose there is no uncertainty regarding the first period. The first good, dollars, may now be taken to form three elementary commodities: (1) sure dollars for consumption during the first period, (2) dollars for consumption in the second period contingent upon the occurence of "wet" and (3) second period dollars contingent upon "dry." Supposing the individual to have a utility function representing his preferences for consumption programs involving these three goods and the proposed dam and supposing that he is endowed with claims against the three types of state/time dependent dollars, we may illustrate his willingness to pay locus in Figure 7.

By aggregating these loci across individuals in the manner suggested earlier one obtains the aggregate willingness to pay locus. As before the project is justifiable if the vector describing its resource costs lies below this aggregate surface. If, for example, all costs are to be incurred during the first period then the relevant measure of benefit is the intersection of the aggregate surface with the "S in period 1" axis.

As in the timeless case this construction supposes either that (1) competitive markets exist for the three types of dollar clains or that (2) the method of financing the project involves time and state dependent payments compatible with an efficient aljocation. In either case discounting is done implicitly at a riskless rate. This may be shown as follows. At the payments points associated with an efficient collection scheme the marginal rate of substitution between any two types of dollars is the same for all individuals. Thus relative "shadow prices" for the three types of dollars are determined. By choosing " $\$$ in 
$-20 a-$

$\sin$ period 2 if "dry"

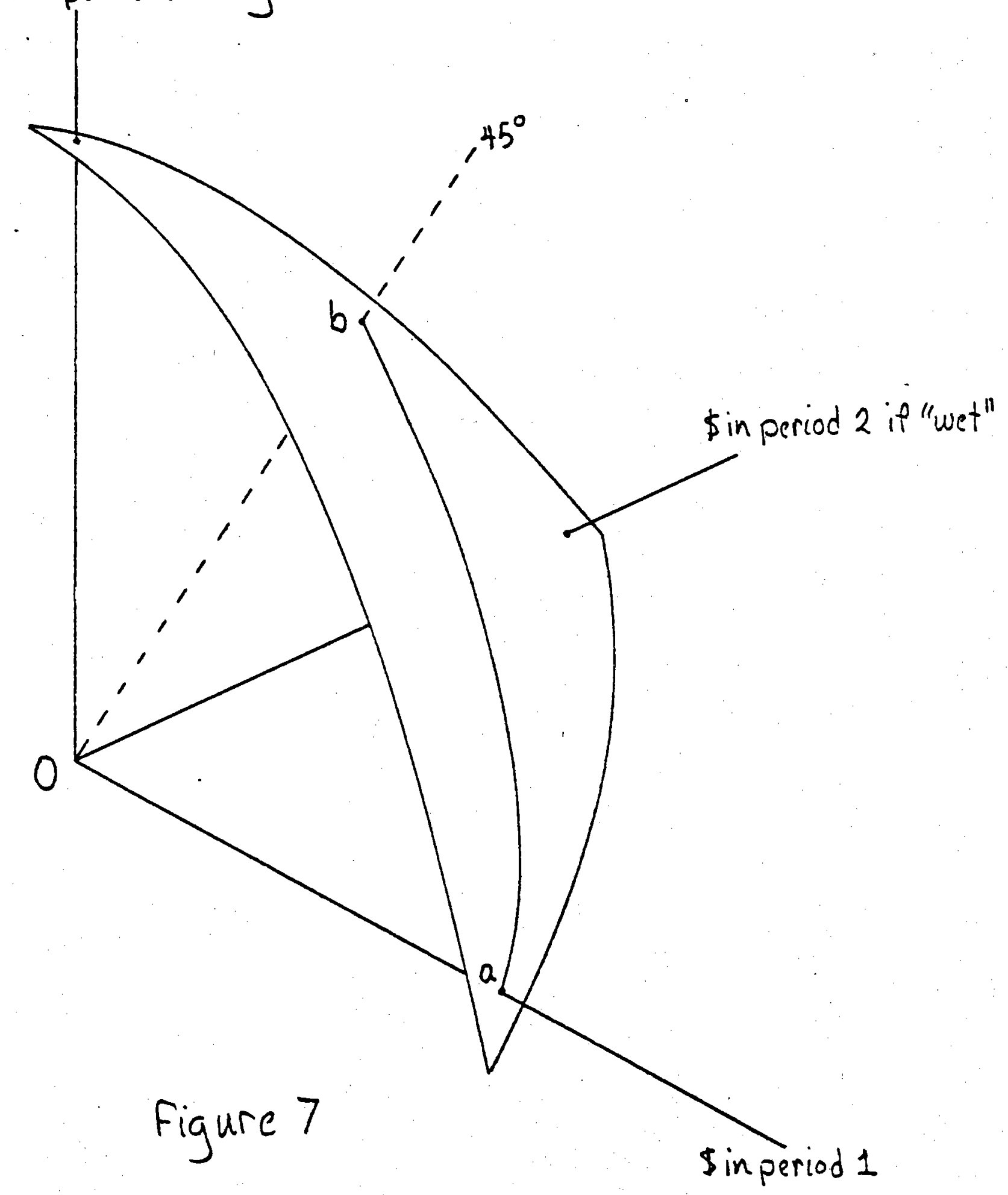


period 1" as numeraire (by letting its price equal one) we can solve uniquely for $p_{W}$ and $p_{D}$ as the prices (in terms of sure period 1 dollars) of claims paying one dollar in period 2 if "wet" occurs and one dollar in period 2 if "dry" occurs, respectively. Since one can purchase at these prices claims assuring a sure dollar in period 2 at a cost of $P_{W}+P_{D}$ in period 1 dollars, it follows that the riskless discount rate is given by

$$
\frac{1}{I+r}=P_{W}+P_{D}
$$

${ } P_{W}+P_{D}$ invested in period 1 at rate $r$ returns one sure dollar in period 2). Now suppose an individual is willing to make payments of $\left(a, b_{W^{\prime}} b_{D}\right)$ in the three types of dollar claims. The present value (the value in terms of period 1 dollars) of this payments program is

$$
v=a+p_{W} b_{W}+p_{D} b_{D}
$$

Alternatively, the value of period 2 payments in terms of sure period 2 dollars is

$$
b=\frac{P_{W}}{P_{W}+P_{D}} b_{W}+\frac{P_{D}}{P_{W}+P_{D}} b_{D}
$$

which implies that

$$
\frac{1}{1+r} b=\left(p_{W}+p_{D}\right) \frac{p_{W} b_{W}+P_{D} b_{D}}{P_{W}+P_{D}}=P_{W} b_{W}+p_{D} b_{D}
$$


or that

$$
v=a+\frac{1}{1+r} b
$$

The case of individual-insurable risk illustrated in the Yellowstone Park example again represents an interesting special case. By making the analogous modification to two periods and adopting the obvious notation the relative price $p_{1} / p_{2}$ will in this case equal the relative probabilities of state 1 versus state 2. Here the present value of a payments program is obtained by discounting the expected value of period 2 payments at the riskless rate corresponding to

$$
\frac{1}{1+r}=p_{1}+p_{2}
$$

This results from the fact that if

$$
p_{1} / p_{2}=.3 / .7=\text { "odds" on state } 1
$$

then

$$
p_{1} /\left(p_{1}+p_{2}\right)=.3=\text { probability of state } 1
$$

and

$$
p_{2} /\left(p_{1}+p_{2}\right)=.7=\text { probability of state } 2
$$


Thus a payment program $\left(a, b_{1}, b_{2}\right)$ would have a present value of

$$
v=a+p_{1} b_{1}+p_{2} b_{2}=a+\frac{1}{1+r} b
$$

where

$$
\begin{aligned}
b & \equiv \frac{p_{1}}{p_{1}+p_{2}} b_{1}+\frac{p_{2}}{p_{1}+p_{2}} b_{2} \\
& =.3 b_{1}+.7 b_{2} \\
& \equiv \text { expected value of }\left(b_{1}, b_{2}\right)
\end{aligned}
$$

Second best considerations remain crucial in the temporal case. A method appropriate to cases of incomplete markets and sure collection schemes can be illustrated with an example. In the case of the dam, suppose that a market exists in which individuals can exchange period 1 dollars and sure period two dollars. On the other hand, no markets for trade in claims contingent upon the occurence of "wet" or "dry" exist. Although the individual depicted in Figure 7 is prepared to make any of the payments combinations along his willingness to pay surface the available market only allows payments lying within the plane determined by the " $\$$ in period 1 " axis and the $45^{\circ}$ line lying between the " $\$$ in period 2 if wet" and the "\$ in period 2 if dry" axes. That portion of his willingness to pay surface which lies in this plane is relevant to this incomplete market case and is reproduced in Figure 8 . Once again 
$-23 a-$

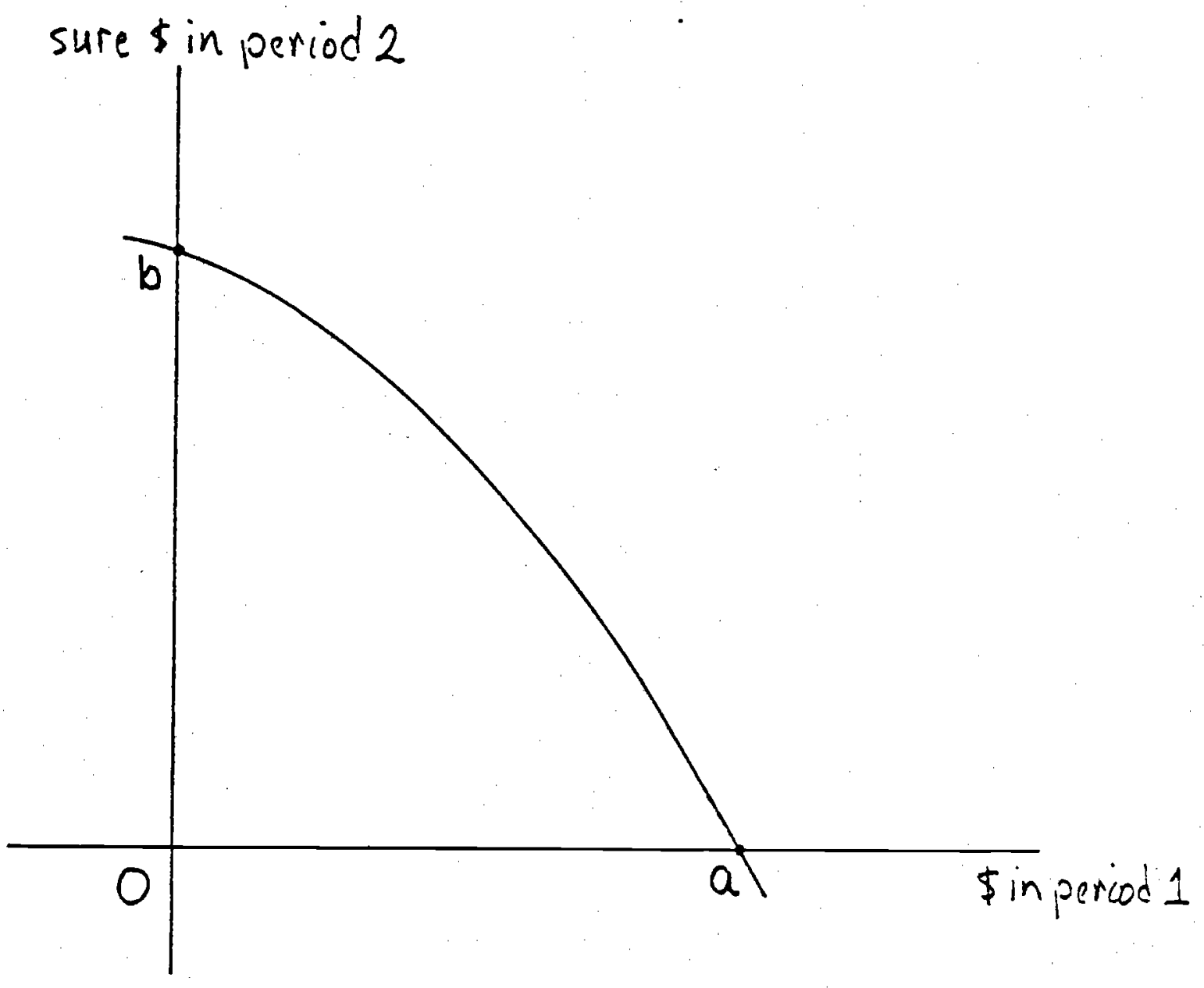

Figure 8 
it is possible to aggregate the willingness to pay schedules of individuals to obtain the aggregate locus depicted in Figure 9 for the case of two Individuals. Here the maximum payment that society would willingly make for the dam in period 1 dollars is given by $0_{1} 0_{2}$. Implicit in this aggregate payment is the fact that the first individual "borrows" an amount $o_{1}$ a from the second at the riskless rate corresponding to

$$
1+r \equiv \tan \theta
$$

Equivalently, the present value of benefits for each individual is computed by discounting his willingness to pay at this riskless rate. Notice that this analysis in no way assumes the existence of markets allowing trade in contingent claims. Discounting at the riskless rate is the direct consequence of the existence of a market for exchange of riskless claims. ${ }^{10}$

${ }^{10}$ The matter of discounting for risk may be clarified by a complete market example. Suppose there are $s$ states with $\pi_{s}$ denoting the objective probability of state $s$. Complete contingent claims markets exist with $p_{s}$ the current price of a claim to one dollar in period two contingent upon the occurence of $s$. The riskless discount rate is then $1 /(1+r) \equiv \sum_{s} p_{s}$. Suppose now that ownership of an asset, a, entails claims to a dollars in period two if state $s$ occurs $s=1, \ldots . s$. The current market price of this asset must be $v=\sum_{s} p_{s} a_{s}$. This market value may also be calculated by determining the value of the asset in period two sure dollars $\sum_{s}\left(p_{s} / \sum_{j} p_{j}\right) a_{s}$ and then discounting at the riskless rate

$$
\begin{aligned}
v & =1 /(1+r) \sum_{s}\left(p_{s} / \sum p_{j}\right) a_{s} \\
& =\left(\sum p_{j}\right) \sum\left(p_{s} / \sum p_{j}\right) a_{s} \\
& =\sum p_{s} a_{s}
\end{aligned}
$$


$-24 a-$

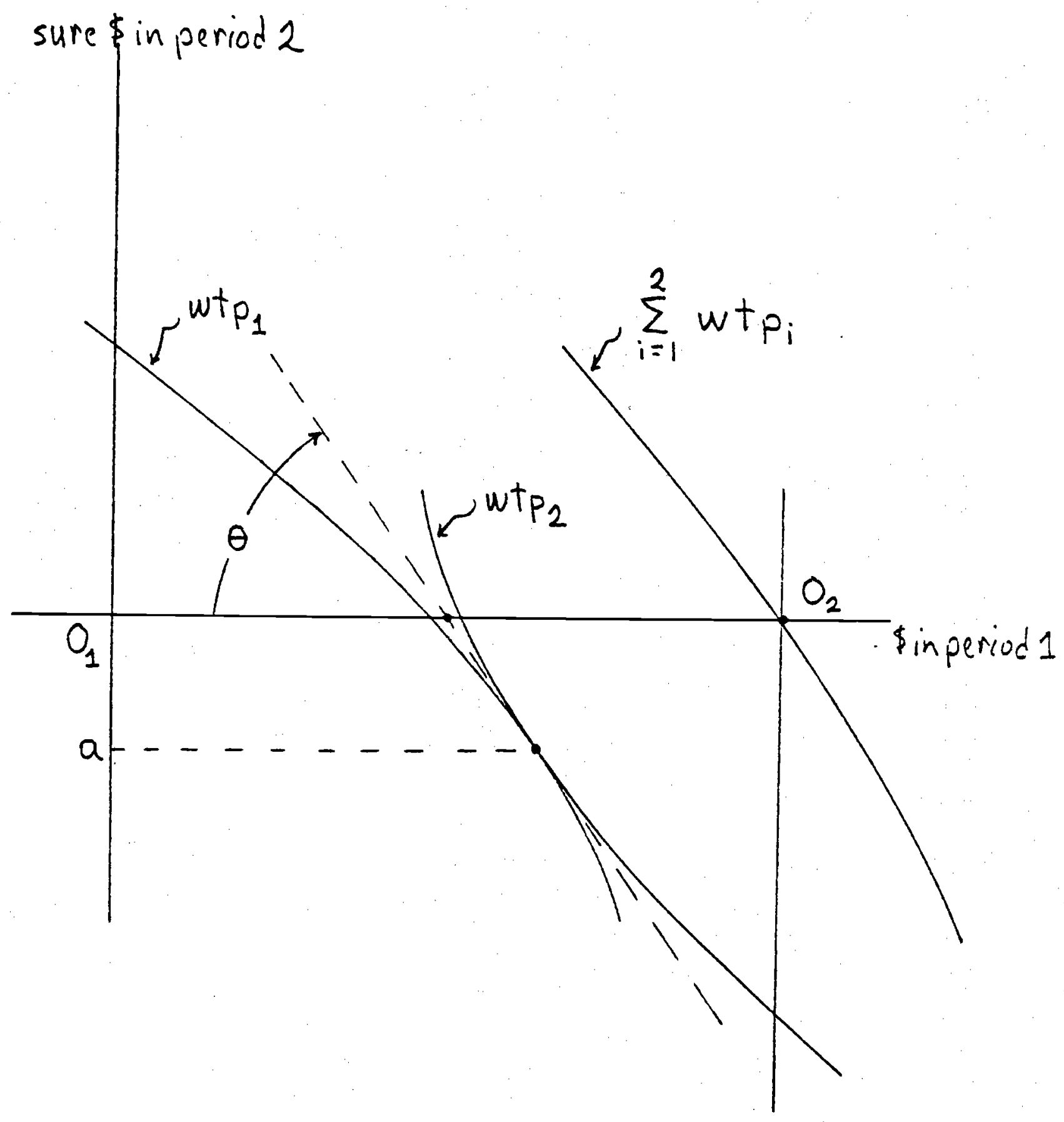

Figure 9 


\section{Generalizations}

The approach to the illustrative cases examined thus far may easily be generalized to situations involving an arbitrary number of periods and states. Consider a general situation involving $S$ states and $Q+1$ periods and suppose that markets exist in which individuals can exchange current sure (time zero) dollars for $M$ different types of assets. Ownership of one unit of the $i^{\text {th }}$ asset entails claims to receipts of

$$
\begin{aligned}
& s=1, \ldots, s \\
& a_{s q}^{1} \quad q=1, \ldots, q \\
& 1=1, \ldots . M
\end{aligned}
$$

dollars at time $q$ (the end of period $q$ ) if state $s$ occurs. For notational convenience let current sure dollars be that asset indexed by zero. A portfolio, then, is an $M+1$ tuple, $x$, where the $1^{\text {th }}$ component, $x_{i}$, denotes the quantity of the $i^{\text {th }}$ asset, $i=0, \ldots .$. . Holding the portfolio

10 (concluded)

Now if one wished to discount the expected value of period two claims rather than their true second-period market value then one would require the risky discount rate corresponding to

$$
1 /(1+0) \sum_{s} \pi_{s} a_{s}=\sum_{s} p_{s} a_{s}=v
$$

If market prices were proportional to probabilities, $\pi_{1} / \pi_{j}=p_{1} / p_{j}$ for all $1, j$, then $\pi_{s}=p_{s} / \Sigma p_{j}$ and $0=I$. In general, however, market prices are not proportional to probabilities and $p \neq I$. In such circumstances the use of $p$ represents nothing more than a correction factor for having used probabilities rather than prices to measure the future value of receipts. 
$x$ thus entitles the owner to $x_{0}$ current sure dollars and claims paying

$$
\sum_{1=1}^{M} x_{1} a_{s q}^{i} \quad \begin{aligned}
& s=1, \ldots, s \\
& q=1, \ldots, Q
\end{aligned}
$$

dollars at time $q$ if state $s$ occurs. In vector notation we have

c $=\mathrm{Ax}$

where

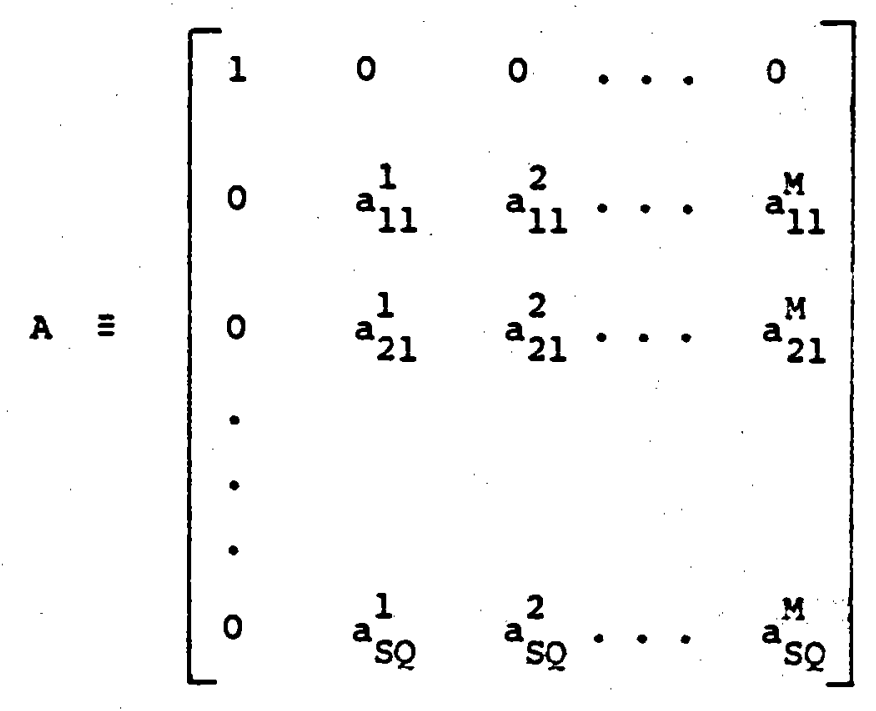

and $c$ is the $S Q+1$ vector of time-state dependent dollar claims associated with the portfolio $x$.

The utility function of the individual for consumption programs involving the $S Q+1$ possible types of time-state dependent clains, $U(c)$, can be used to derive a utility function for portfolios by defining the 
utility of the portfolio to be equal to the utillty of the associated vector of time-state dependent claims: 11

$$
u(x) \equiv u(A x)
$$

Sinflarly, if the list of goods is expanded to include the services to be derived from a proposed public project, then the notation $u(x, \delta)$ may be used to denote the utility of holding the portfolio $x$ when the services are provided $(\delta=1)$ and when the services are not provided $(\delta=0)$. Supposing the individual to be endowed, following market trade, with the portfolio e the willingness to pay locus may be defined as consisting of those vectors $Y$ which satisfy

$$
u(e-Y, 1)=u(e, 0)
$$

Aggregation across individuals may then be accomplished in the manner suggested earlier and our previous analysis applied. In particular, the matter of risk discounting may be examined as follows. Suppose the markets for assets afford opportunities for riskless investments, i.e., there exist portfolios $x^{t}$ satisfying

$$
\sum_{i} x_{i}^{t} a_{s q}^{i}= \begin{cases}1 & s=1, \ldots, s \\ & q=t \\ 0 & \text { otherwise }\end{cases}
$$

${ }^{11}$ Notice that this general formulation requires only that an individual have a utility function ranking altemative consumption programs. This is less restrictive than the von Neuman-Morgenstern formulation and compatible with other approaches, e.g., the certainty-equivalence formulation of Handa (1977). 
Eor $t=1, \ldots, Q$. Cownership of $x^{t}$ returns a sure dollar at time $t$ and nothing at other times.) The existence of these riskless portfolios establishes the riskless discount rates applicable to returns at time $t$ as

$$
1 /\left(1+r_{t}\right) \equiv p x^{t} \quad t=1, \ldots, Q
$$

where $p \equiv\left(1, p_{1}, \ldots, p_{M}\right)$ is the vector of time zero sure dollar-prices of the assets. Now suppose another portfolio, $x_{j}$ offers risky returns at time $T$, i.e.

$$
\sum_{i} x_{i} a_{s q}^{i}= \begin{cases}z_{s} & s=1, \ldots, s \\ 0 & \text { otherwise }\end{cases}
$$

The current market price of this risky portfolio must be px. This present value may equivalently be detemined by noting that the ratio $\mathrm{px} / \mathrm{px}{ }^{\mathrm{T}}$ represents the price of the risky portfolio in terns of time $T$ sure dollars. This is the future, time $T$, value of the risky portfolio. To determine its present value notice that

$$
\mathrm{px} / \mathrm{px}=\mathrm{px}\left(1+r_{T}\right)
$$

or that

$$
\mathrm{px}=1 /\left(1+r_{T}\right) \frac{\mathrm{px}}{\mathrm{px}}
$$

Thus the present value of the risky portfolio is obtained by discounting Its future value at the riskless rate. Again, this is the direct result 
of the existence of markets which afford opportunities for riskless investment.

It should be noticed that this analysis supposes only that free competitive exchange is possible in the existing markets for assets. Although this is not equivalent to assuming the existence of complete contingent claims markets it does include the case of complete markets as a possible special case. To see this notice first that the ability to buy and sell assets at prices

$$
p=\left(1, p_{1}, \ldots, p_{M}\right)
$$

implies that an individual endowed with the portfolio e faces the "portfolio" budget constraint

$$
\mathrm{px}=\mathrm{pe}
$$

Suppose now that the rank of $A$ is equal to $S Q+1, i . e .$. there are as many linearly independent assets as there are types of contingent dollar claims. Then we may write

$$
x=A^{-1} c
$$

and the portfolio budget constraint is equivalent to the "contingent claim" budget constraint given by

$$
\mathrm{PC}=\mathrm{PE}
$$

where $E \equiv A e$ and $P \equiv \mathrm{pA}^{-1}$. Here the ability to buy and sell assets at 
prices $p$ is equivalent to the ability to buy and sell contingent claims at prices P. This situation is therefore equivalent to one in which complete markets exist for trade in contingent claims. In general, however, the rank of $A$ may be less than $S Q+1$ in which case existing markets for assets do not provide opportunities for exchange of risk equivalent to those which would be afforded by a complete set of contingent claims markets. 12

${ }^{12}$ For a general discussion of the relationship of the rank of the assets matrix to the opportunities for achieving efficient distributions of risk see Ross (1976). 


\section{APPENDIX}

Here we examine the relationships among the fair-bet, certainty and surplus points defined in section 2. The fair bet and certainty points are closely related and may, in certain circumstances, coincide. Suppose, for example, that $U_{W}$ and $U_{D}$ are the same functional forms.

Then

$$
\begin{aligned}
& v_{W}\left(e_{W}-\gamma_{W}^{*}, 1\right)=U_{D}\left(e_{D}-\gamma_{D^{\prime}}^{*} 1\right) \\
& \text { Iff } e_{W}-\gamma_{W}^{*}=e_{D}-\gamma_{D}^{*}
\end{aligned}
$$

Similarly,

$$
\begin{aligned}
& \nabla_{W}^{\prime}\left(e_{W}+\gamma_{W^{\prime}}^{\prime} l\right)=U_{D}^{\prime}\left(e_{D}-Y_{D^{\prime}}^{\prime} 1\right) \\
& \text { Iff } e_{W}-Y_{W}^{\prime}=e_{D}-\gamma_{D}^{\prime}
\end{aligned}
$$

In this case the certainty point and the fair bet point coincide. This may also occur under more general circumstances as can be seen by making use of the "ransom" approach developed in Cook and Graham (1977) and defining $R(e)$ by the requirement

$$
U_{W}(e-R(e), 1)=U_{D}(e, 1)
$$

Notice that $R$ represents the maximum amount an individual endowed with a certainty of a dry year and dollar clains of e would pay to obtain a 


\section{A -2}

certainty of a wet year. (R may either be positive or negative depending upon which state is preferable.) Thus $R$ represents a measure of the extent to which the state "wet" is in itself preferred to the state "dry" (or vice versa). Differentiating both sides with respect to e we obtain

$$
U_{W}^{\prime}(e-R(e), 1)\left[1-R^{\prime}(e)\right]=U_{D}^{\prime}(e, 1)
$$

Now if $R^{\prime}(e)$ is zero, i.e., there is no effect of a change in encowed wealth upon the "ransom" the individual would pay, then

$$
U_{W}^{\prime}(e-R(e), 1)=U_{D}^{\prime}(e, 1)
$$

In this case the certainty point and the fair bet point again coincide as can be seen by letting $e=e_{D}-Y_{D}^{k}$ and making use of equations $(6),(7)$, and (8). In general we may state that

$$
U_{W}^{\prime}(e-R(e), 1) \stackrel{\sum}{\Sigma} U_{D}^{\prime}(e, 1) \text { as } R^{\prime}(e) \stackrel{\geq}{\gtrless} 0
$$

or that

$$
U_{W}^{\prime}\left(e_{W}-Y_{W^{\prime}}^{*} 1\right) \stackrel{\sum}{\sum} U_{D}^{\prime}\left(e_{D}-Y_{D}^{*}, 1\right) \text { as } R^{\prime}\left(e_{D}-Y_{D}^{*}\right) \geq 0 \text {. }
$$

This means that the fair bet point lies along the willingness to pay locus to the left or to the right of the certainty point depending upon whether $R^{\prime}$ is positive or negative. 


\section{A -3}

Turning now to the surplus point we see that if

$$
v_{W}\left(e_{W}, 0\right)=u_{D}\left(e_{D}, 0\right)
$$

(the famer is endowed with claims that leave him indifferent as to which state, "wet" or "dry," occurs in the absence of the dam) then

$$
\left.v_{W}\left(e_{W}-s_{W^{\prime}} 1\right)=v_{D}\left(e_{D}-s_{D^{\prime}}, 1\right) \quad \text { (by equation } 1\right)
$$

and

$$
\left(r_{W^{\prime}}^{\star}, r_{D}^{\star}\right)=\left(S_{W^{\prime}}, S_{D}\right)
$$

(by equation 6)

In this case the certainty point and the surplus point coincide. In general the surplus point lies along the willingness to pay locus to the left or to the right of the certainty point depending upon whether "wet" or "dry" is preferred in the original endowment, i.e., upon whether

$$
\nabla_{W}\left(e_{W^{\prime}}, 0\right) \geq D_{D}\left(e_{D^{\prime}}, 0\right)
$$


REFERENCES

Arrow, K.J. (1964), "The Role of Securities in the Optimal Allocation of Risk-bearing," Review of Economic Studies, Vol. 31, pp. 91-6.

Arrow, K.J. and Lind, R.C. (1970), "Uncertainty and the Evaluation of Public Investment Decisions," American Economic Review, Vol. 60, pp. 364-78.

Cicchett, C.J. and Freeman, A.M., (1971), "Option Demand and Consumers Surplus: Further Comment," Quarterly Journal of Economics, Vol. 85, pp. 528-39.

Cook, Philip J. and Graham, Daniel A. (1977), "The Demand for Insurance and Protection: The Case of Irreplaceable Comnodities," Quarterly Journal of Economics, Vol. 91, pp. 143-54.

Henry, Claude (1974), "Option Values in the Economics of Irreplaceable Assets," Review of Economic Studies, symposium on the Economics of Exhaustible Resources, pp. 89-104.

Handa, Jagdish (1977), "Risk, Probabilities, and a New Theory of Cardinal Utility." Journal of Political Economy, Vol. 85, pp. 97-122.

Hirshleifer, J. (1965), "Investment Decision Under Uncertainty: ChoiceTheoretic Approaches," Quarterly Journal of Economics, Vol. 79, pp. 509-36.

Lindsay, C.M. (1969), "Option Demand and Consumer's Surplus," Quarterly Journal of Economics, Vol. 83, pp. 344-46.

Long, M.F. (1967), "Collective-Consumption Services of IndividualConsumption Goods: Comment," Quarterly Journal of Economics, Vol. 81, pp. 351-52.

Malinvaud, E. (1973), "Markets for an Exchange Economy with Individual Risks," Econometrica, Vol. 41, pp. 383-410.

Ross, Stephen A. (1976), "Options and Efficiency," Quarterly Journal of Economics, Vol. 90, pp. 75-89.

Schmalensee, Richard (1972), "Option Demand and Consumer's Surplus: Valuing Price Changes Under Uncertainty," American Economic Review, Vol. 62, pp. 813-24.

Weisbrod, B.A. (1964), "Collective Consumption Services of Individual Consumption Goods," guarterly Journal of Economics. Vol. 77, pp. 71-77. 